\title{
Flórula do Morro \\ dos Perdidos, Serra de Araçatuba, Paraná, Brasil: Ericaceae
}

\author{
Floristic survey of the Morro dos Perdidos, \\ Serra de Araçatuba, Paraná, \\ Brazil: Ericaceae
}

\section{RosiLENE RodRigues SILVA ${ }^{1}$ \\ Armando Carlos Cervi ${ }^{2}$ Élide Pereira dos SANTOS ${ }^{2}$}

A família Ericaceae Juss. possui distribuição cosmopolita, incluindo cerca de 130 gêneros e 3000 espécies. No Brasil, ocorrem 12 gêneros e cerca de 100 espécies (Luteyn, 1989, 1992; Silva \& CERVI 1999, 2006).

O Morro dos Perdidos é uma área de proteção ambiental bem preservada, recoberta por Floresta Atlântica. O projeto "Flórula do Morro dos Perdidos" foi iniciado em 1995 e foram publicadas as seguintes famílias: Passifloraceae (Cervi \& SANTos, 2000), Plantaginaceae (Hefler et al., 2003), Clusiaceae (SLuSARSKI et al., 2003), Iridaceae (VIEIRA et al., 2003) e Ochnaceae (SALVADOR et al., 2005).

O objetivo deste trabalho foi realizar o levantamento da família Ericaceae no Morro dos Perdidos, contribuindo para o conhecimento da família no Estado do Paraná.

\footnotetext{
${ }^{1}$ Universidade Federal do Mato Grosso, Seção de Curadoria, Herbário UFMT, CEP: 78060900, Cuiabá, MT, Brasil. Bolsista Desenvolvimento Científico Regional CNPq (rrodrigues98@ hotmail.com). ${ }^{2}$ Universidade Federal do Paraná, Setor de Ciências Biológicas, Departamento de Botânica, Caixa Postal 19031, CEP 81531-970, Curitiba, PR, Brasil. Bolsistas de Produtividade em Pesquisa do CNPq.
} 


\section{MATERIALEMÉTODOS}

O Morro dos Perdidos localiza-se na Serra de Araçatuba, município de Guaratuba, Paraná $\left(25^{\circ} 45^{\prime}-25^{\circ} 50^{\prime} \mathrm{S}\right.$ e $\left.49^{\circ} 03^{\prime}-49^{\circ} 06^{\prime} \mathrm{W}\right)$. Trata-se de uma área particular de aproximadamente 600 alqueires, altitude máxima de 1.439 m que se encontra nos domínios da Floresta Ombrófila Densa (Floresta Atlântica).

Foram realizadas coletas mensais, de forma casual, de outubro/1999 a abril/2007. O material coletado está depositado nos herbários do Departamento de Botânica da Universidade Federal do Paraná (UPCB) com duplicatas nos Herbários do Museu Botânico Municipal (MBM) e do New York Botanical Gardens (NY).

A identificação do material foi realizada a partir da análise morfológica detalhada, com auxílio de chaves analíticas, descrições e diagnoses encontradas na literatura específica. Foram consultados materiais dos herbários HUCP, MBM, UPCB, acrônimos segundo HolmGREN et al. (1990).

A chave para separação das espécies, as descrições e ilustrações foram elaboradas com base apenas no material proveniente do Morro dos Perdidos.

\section{RESULTADOS EDISCUSSÕES}

A família Ericaceae apresenta uma grande diversidade de espécies na área, tendo uma distribuição restrita à floresta ombrófila densa altomontana, a partir de $1000 \mathrm{~m}$ s.n.m.. Está representada no Morro dos Perdidos por cinco táxons pertencentes a três gêneros: Agarista niederleinii (Sleumer) Judd var. niederleini, Gaultheria itatiaiae Wawra, Gautheria serrata var. organensis (Meissn.) Luteyn, Gaylussacia arassatubensis R.R. Silva \& Cervi e Gaylussacia brasiliensis (Spreng.) Meissn. var. brasiliensis.

\section{Família Ericaceae}

Ervas, subarbustos, arbustos ou árvores; folhas simples, alternas, sem estípulas. Inflorescência terminal ou axilar, flores vistosas, bissexuadas, actinomorfas, geralmente pentâmeras, gamossépalas e gamopétalas, pétalas frequentemente urceoladas, androceu diplostêmone, anteras poricidas, ovário súpero ou ínfero; fruto cápsula loculicida, septicida, baga ou drupa. 


\section{Chave Para os táXons de ERICACEAe EnCONTRAdos no MORRO DOS PERDIDOS}

1. Ovário súpero, fruto cápsula 2

Ovário ínfero, fruto drupa 4

2. Filetes geniculados, ciliados ... Agarista niederleinii var. niederleinii Filetes subulados, papilosos ou pubérulos 3

3. Corola cilíndrico-campanulada; cálice com lacínios estreito-triangulares . . . . . Gaultheria itatiaiae

Corola urceolada; cálice com lacínios ovalado-acuminados . . . . . . . . . . . . Gaultheria serrata var. organensis

4. Corola alva, campanulada. . . . . . . . Gaylussacia arassatubensis Corola rósea a vermelha, cilíndrico-urceolada. . . . . . . . . . . . . . . . . . . . . . . . Gaylussacia brasiliensis var. brasiliensis

Agarista niederleinii (Sleumer) Judd var. niederleinii, J. Arnold, Arbor 65: 329. 1984. [Fig. 1 A-F]

Arbustos a árvores, 2-4 m alt. Ramos delgados, eretos, cilíndricos, pubescentes a glabros. Folhas coriáceas, glabras a esparsamente pubescentes na nervura central, pecioladas, pecíolo 1,5-5 $\mathrm{mm}$ de compr., pubérulo; lâminas $1-5 \times 0,5-1,8 \mathrm{~cm}$, ovaladas a lanceolado-oblongas, base cordada a truncada, ápice arredondado a agudo-mucronado, margem inteira, levemente convexa. Inflorescência axilar, racemosa, 1,5-3,5 ($4,5) \mathrm{cm}$ compr.; bráctea ca. 1,5 mm compr., triangular; bractéolas duas, $1,7 \mathrm{~mm}$ de compr., triangulares, alternas a opostas. Flores pediceladas, pedicelo 4-6 $\mathrm{mm}$ de compr. Cálice ca. $3 \mathrm{~mm}$ de compr., glanduloso externamente, pubérulo internamente, lacínios ovalados, ápices acuminados, ligeiramente ciliados. Corola alva, alvo-esverdeada a creme, 5-8 x 2-5 mm, cilíndrica, carnosa, glabra. Estames com filetes geniculados, achatados, margem ciliada, anteras 0,9-1,4 mm de compr. Ovário súpero, esparsamente piloso a glabro; estilete glabro, 4-7 mmm de compr. Cápsula 4,5-8 x 5,5-9 mm, subglobosa, pilosa a glabra.

Material examinado - Paraná, Município de Guaratuba, Serra de Araçatuba, Morro dos Perdidos, 27/XI/1998, fl., Santos et al. 672 (UPCB). Idem, 22/I/1999, fl. Silva \& Santos 64 (UPCB). Idem, 17/ XII/1999, fl., Santos, Cervi \& Socher 861 (UPCB).

Distribuição geográfica - Restrita aos estados do Sul do Brasil (KINOSHITA \& ROMÃo, 2010). 
Observações ecológicas. No Morro dos Perdidos, é encontrada nos diversos habitats: campos de altitude, campos rupestres e no interior de floresta ombrófila densa altomontana (floresta nebular), entre 1200 e $1350 \mathrm{~m}$ de altitude.

\section{Gautheria itatiaiae Wawra, Oest. Bot. Zeitschr. 31: 280. 1881.}

[Fig.2 A-H]

Arbustos 0,3 a $1 \mathrm{~m}$ alt. Ramos com tricomas cerdosos. Folhas coriáceas, pubérulas a glabras, face abaxial com tricomas longos, estrigosos, caducos, pecioladas, pecíolo $2-4 \mathrm{~mm}$ de compr., caniculado na face adaxial; lâminas $(0,8-)$ 1,8-3,5 x 0,4-1,6 cm, ovaladas a elípticas, base arredondada a obtusa, ápice acuminado a agudo, margem crenada, cada dente terminando em um tricoma caduco. Inflorescências terminais, racemosas; bráctea 1-1,5 $\mathrm{mm}$ compr, lanceolada, estriada; bractéolas duas, 1,5-3 x 1,8 mm., involucrais, ovaladas. Flores pediceladas, pedicelos 3-6 mm de compr. Cálice 3,5-6 x 1,3-1,6 mm, externamente estrigoso, internamente pubérulo, lacínios estreito-triangulares, profundamente 5partidos, ápice agudíssimo, raro ultrapassando a corola. Corola 4-7 x 2$4,8 \mathrm{~mm}$, alva a rosada, cilíndrico-campanulada, externamente glabra, internamente pilosa na porção mediana. Estames com filetes subulados, papilosos, anteras 1,5-2 $\mathrm{mm}$ de compr. Ovário súpero, com tricomas amarelados a esbranquiçados; estilete pubérulo, 3,5-5 $\mathrm{mm}$ de compr. Cápsula ca. $4 \mathrm{~mm}$ de compr., pubescente, depresso-globosa.

Material examinado - Paraná, Município de Guaratuba, Serra de Araçatuba, Morro dos Perdidos, 22/I/1999, fl., Silva \& Santos 65 (UPCB).

Distribuição GeOgRÁFICA — No Brasil, é encontrada desde a Bahia, Minas Gerais até o Rio Grande do Sul (Kinoshita \& Romão, 2010).

ObSERVAÇões eColóGICAS - No Morro dos Perdidos, foi coletada uma única vez, em borda de floresta ombrófila densa altomontana, a $1.400 \mathrm{~m}$ de altitude.

Gautheria serrata var. organensis (Meisn.) Luteyn.,

Mus. Paraense E. Goeldi, sér. Bot. 7(2): 324. 1991

[Fig. $3 \mathrm{~A}-\mathrm{G}$ ]

Arbustos 0,3-1,5 m alt. Ramos com tricomas hirsuto-ferrugíneos a glabros. Folhas coriáceas, hirsutas em ambas as faces, tricoma estrigoso, caduco, punctadas após a queda dos tricomas, pecioladas, pecíolo 3-4 
mm de compr.; lâminas 2,8 x 0,9-3,7 cm, elípticas a oblongas, base arredondada a obtusa, ápice agudo a arredondado, margem crenada, cada crena terminando em um tricoma, caduco. Inflorescência terminal a axilar, racemosa, 3-6,5 cm de compr.; brácteas ca. $5 \mathrm{~mm}$ compr, subcoriáceas, estriadas, ovaladas a oblongas, agudas; bractéolas 4,5 × 2-4 mm, ovaladas, estriadas, ciliadas, agudas a acuminadas. Flores com pedicelos de 5-9 mm de compr., hirsutos. Cálice 5-6 mm de compr., pubescente, lacínios ovalado-acuminados, margem ciliada. Corola rósea a vermelha, urceolada, pubescente, 5-7 mm de compr. Filetes subulados, pubérulos, anteras 1,2$2 \mathrm{~mm}$ de compr. Ovário pubescente; estilete 3,5-4 $\mathrm{mmm}$ de compr, pubescente. Cápsula 5-7 mm, globosa, pubescente.

Material eXaminado - Paraná, Município de Guaratuba, Serra de Araçatuba, Morro dos Perdidos, 23/XI/1996, fl., Santos et al. 281 (UPCB) idem, 17.IX.1999, fl., Santos et al. 797 (UPCB).

DistribuiçÃo GeOGRÁFICA — No Brasil, encontrada de Minas Gerais a Santa Catarina (Kinoshita \& Romão, 2010).

Observações ecológicas - No Morro dos Perdidos, ocorre nos campos de altitude a $1200 \mathrm{~m}$ de altitude.

\section{Gaylussacia arassatubensis R.R. Silva \& Cervi., Fontqueria 54 (1): 4.1999.}

[Fig. $4 \mathrm{~A}-\mathrm{H}$ ]

Ervas ca. $15 \mathrm{~cm}$ alt, com xilopódios. Ramos cilíndricos, pubérulos, com tricomas glandulares, caducos. Folhas pecioladas, pecíolo 1-2 mm de compr.; lâminas $0,9-2,3 \times 0,5-1 \mathrm{~cm}$, pubescentes, com tricomas glandulares capitados, caducos, oblongas a obovado-oblongas, base cuneada a obtusa, ápice agudo a obtuso, margem inteiramente serreadocrenada ou apenas na metade superior. Inflorescências axilares subterminais, 3-4,6 cm de compr, avermelhadas; brácteas 4-6 mm de compr., avermelhadas, ovaladas, obovadas a oblongas, glabras, margens ciliadas; bractéolas, 3-4 mm de compr., lanceoladas, avermelhadas, com tricomas glandulares, levemente denteadas, cada dente terminando em um tricoma setoso-glandular, caduco. Flores com pedicelos 3-4 mm de compr., avermelhados, com tricomas glandulares, esparsos. Cálice ca. 2 $\mathrm{mm}$ de compr., avermelhado, campanulado, com tricomas glandulares, caducos, lacínios ovalado-deltoides, com tricomas glandulares, margem ciliada. Corola 4-9 mm de compr, alva, campanulada, com tricomas glandulares, caducos, lobos obtuso-deltóides, 4-9 mm de compr. Filetes subulados, achatados, papilosos, pubescentes, margens ciliadas, anteras ca. 1,7 mm de compr. Ovário glabro; estilete glabro. Frutos não vistos. 
Material examinado - Paraná, Município de Guaratuba, Serra de Araçatuba, 21/I/1994, fl., Silva \& Cordeiro 3383 (MBM); Idem. Morro dos Perdidos, 23/XI/1996, fl., Santos, Fernandes \& Coimbra 278 (UPCB holótipo, MBM isótipo); idem 19.XI.1999, fl., Santos et al. 821 (UPCB).

Distribuição GeOgráfica - No Brasil, ocorre no Paraná e Santa Catarina (KINOSHITA \& Romão, 2010).

ObSERVAÇÕES ECOLÓGICAS - No Morro dos Perdidos, ocorre nos campos de altitude a $1400 \mathrm{~m}$ de altitude.

\section{Gaylussacia brasiliensis (Spreng.) Meisn. var. brasiliensis, Linnaea 8: 499. 1833.}

[Fig. $5 \mathrm{~A}-\mathrm{G}$ ]

Arbustos a arvoretas, 0,3-4 m alt. Ramos flexuosos, pubescentes a glabros, geralmente com tricomas glandulares clavados. Folhas pecioladas, pecíolo 1-4 mm de compr.; lâminas 1,8-6 cm de compr., oblongas, elípticooblongas a obovado-oblongas, base cuneada a arredondada, ápice subagudo, obtuso a arredondado, raro levemente emarginado, com glândula calosa apiculada, margem inteira a denteada no ápice, cada dente terminando em um tricoma glandular, caduco, face adaxial geralmente glabra, face abaxial com tricomas caducos e glândulas clavadas. Inflorescência 2,5-6,5 cm de compr., axilar, racemosa; brácteas 4-8 mm de compr, ovaladas, oblongas, obovadas a lanceoladas, com tricomas glandulares, margem ciliada; bractéolas ca. $6 \mathrm{~mm}$ de compr., setáceas, tricomas glandulares esparsos, margem ciliada. Flores com pedicelos de 2-6 mm de compr., pubescentes. Cálice ca. 1,5 mm de compr., lacínios ovalado-deltoides, ápice agudo, pubescentes, raro com glândulas muricadas na face externa. Corola 7-13 mm de compr., rósea a vermelha, cilíndricourceolada. Filetes subulados, achatados, pubescentes, anteras $2-3 \mathrm{~mm}$ de compr., lineares. Ovário glabro; estilete glabro, 7-9 $\mathrm{mm}$ de compr. Frutos 4-6 mm, drupa 10-sulcadas, pubescente.

Material eXaminado - Paraná, Município de Guaratuba, Serra de Araçatuba, 10/XI/1959, fl., Hatschbach 5563 (MBM); Idem, 15/IX/ 1982, fl., Kummrow 2029 (MBM); Idem, 15/IX/1995, fl., Silva, Poliquesi \& Santos 1510 (MBM); Idem, Morro dos Perdidos, 23/XI/1996, fl., Santos et al. 278a(UPCB); idem 18/IX/1997, fl., fr., Fernandes \& Santos 39 (MBM, UPCB); idem 18/IX/1997, fl., Santos \& Fernandes 341 e 342 (MBM, UPCB); idem 16/X/1998, fl., Cândido \& Hassegawa 1 (UPCB); idem 16/X/1998, fl., Cândido \& Hassegawa 8 (UPCB). Morretes, Serra do Marumbi, 30/VII/1998, fl., Silva et al. 59 (UPCB). 
DistribUiÇão GEOGRÁFICA — Brasil, encontrada da região Centro-Oeste e Nordeste até o Sul do país (Kinoshita \& Romão, 2010).

Observações ecológicas - No Morro dos Perdidos, ocorre nos campos de altitude, entre 1200 e $1400 \mathrm{~m}$ de altitude.

\section{RESUMO}

O estudo da família Ericaceae é parte do levantamento da Flórula do Morro dos Perdidos, Paraná, Brasil. Esta família está representada na área por cinco táxons: Agarista niederleinii (Sleumer) Judd var. niederleinii, Gaultheria itatiaiae Wawra, Gautheria serrata var. organensis (Meissn.) Luteyn, Gaylussacia arassatubensis R.R. Silva \& Cervi e Gaylussacia brasiliensis (Spreng.) Meissn. var. brasiliensis. São apresentados chave, descrições, ilustrações e comentários para estes táxons.

PalaVras-chaVe: Ericaceae; Floresta Atlântica; Paraná; Brasil

\section{SUMMARY}

The study of the family Ericaceae is part of the project of "Florula of the Morro dos Perdidos, Serra de Araçatuba, Paraná, Brasil". In that area, the family is represented by five: garista niederleinii (Sleumer) Judd var. niederleinii, Gaultheria itatiaiae Wawra, Gautheria serrata var. organensis (Meissn.) Luteyn, Gaylussacia arassatubensis R. R. Silva \& Cervi e Gaylussacia brasiliensis (Spreng.) Meissn. var. brasiliensis. A key, descriptions, illustrations and notes of these species are provided.

KEY wORDS: Ericaceae; Atlantic Forest; Paraná; Brazil

\section{RÉSUMÉ}

L'étude de la famille Ericacées fait partie du projet "Florula do Morro Perdidos, Serra de Araçatuba, Paraná, Brasil". Dans cette aire géographique, la famille est représentée par cinq taxa: Agarista niederleinii (Sleumer) Judd var. niederleinii, Gaultheria itatiaiae Wawra, Gautheria serrata var. organensis (Meissn.) Luteyn, Gaylussacia arassatubensis R. R. Silva \& Cervi e Gaylussacia brasiliensis (Spreng.) Meissn. var. brasiliensis. Ce travail incluit une clef, des descriptions, des illustrations et des notes de ces espèces.

Mots CLÉs: Ericaceae; Florêt Atlantique; Paraná; Brésil 


\section{BIBLIOGRAFIA}

Cervi A. C., E. P. Santos. 2000. Flórula do Morro dos Perdidos, Serra de Araçatuba, Estado do Paraná, Brasil: Passifloraceae. Estudos de Biologia. 22 (46): 25-47.

Hefler S. M, A. C. Cervi \& E. P. Santos. 2003. Flórula do Morro dos Perdidos, Serra de Araçatuba, Estado do Paraná, Brasil: Plantaginaceae. Estudos de Biologia. 25 (50): 17-21.

Holmgren P. K., N. H. Holmgren \& L. C. Barnett. 1990. Index Herbariorum. $8^{\mathrm{a}}$ ed. New York (EUA): International Association for Plant Taxonomy.

Kinoshita, L. S. \& G. O. Romão. 2010. Ericaceae in Lista de Espécies da Flora do Brasil. Jardim Botânico do Rio de Janeiro. <http:// floradobrasil.jbrj.gov.br/2010/FB007454>.

LuteYn, J. L. 1989. The genus Gaultheria in Brazil. Bol. Mus. Paraense Emílio Goeldi, ser. Bot. 7 (2): 309-331.

Luteyn, J. L. 1995. Ericaceae Part II. In Flora Neotropica. Monogr. 66: $1-556$.

Salvador G.S, E.P Santos \& A. C. Cervi. 2005. Flórula do Morro dos Perdidos, Serra de Araçatuba, Estado do Paraná, Brasil: Ochnaceae. Estudos de Biologia 27 (61): 13-17.

Silva R.R \& A. C. Cervi. 1999. Gaylussaciae novae (Ericaceae) Brasilia australi nuper inventae. Fontqueria, 54 (1):1-6.

Silva R. R, A. C. Cervi. 2006. Ericaceae Juss. nativas no Estado do Paraná, Brasil. Acta Biol. Par. 35 (1-2): 1-45.

Slusarski S.R, A. C. Cervi, O. A. Guimarães \& E. P. Santos. 2003. Flórula do Morro dos Perdidos, Serra de Araçatuba, Estado do Paraná, Brasil: Clusiaceae, gênero Hypericum L. Estudos de Biologia. 25 (50): 23-28.

Vieira E.R, Santos E.P \& Tardivo R.C. 2003. Flórula do Morro dos Perdidos, Serra de Araçatuba, Estado do Paraná, Brasil: Iridaceae. Estudos de Biologia. 25 (51): 17-29. 


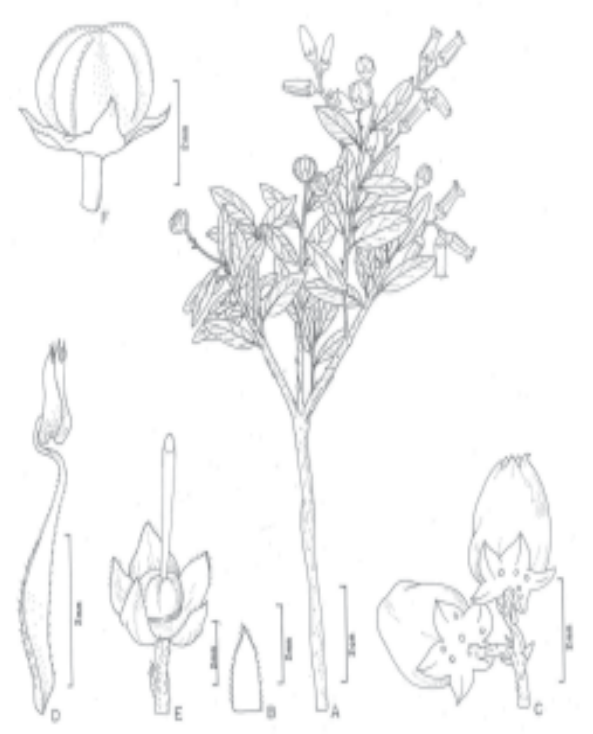

Fig. 1. Agarista niederleinii (Sleumer) Judd var. niederleinii. A, ramo fértil. B, detalhe da bráctea. C, flor. D, estame. E, gineceu. F, fruto (Silva \& Santos 64, UPCB). [Ilustração realizada por Dalton T. Renault].

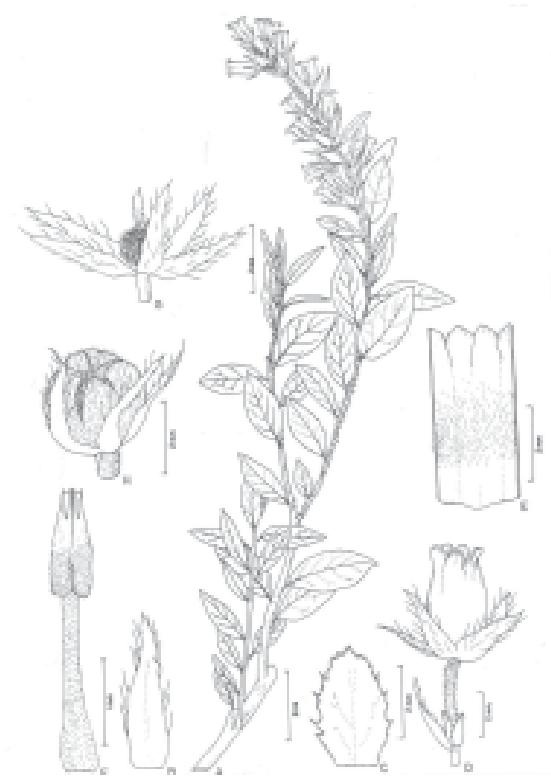

Fig. 2. Gaultheria itatiaie Wawra. A, ramo fértil. B, detalhe da bráctea. C, vista frontal da bractéola. D, flor. E, corola em vista frontal. F, estame. G, gineceu. H, fruto (Silva \& Santos 65, UPCB). [Ilustração realizada por Dalton T. Renault]. 


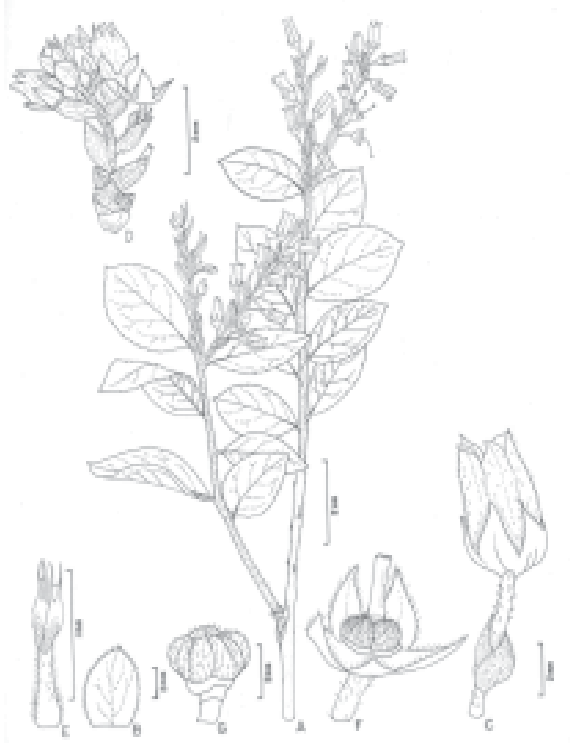

Fig. 3. Gaultheria serrata var. organensis (Meisn.) Luteyn. A, ramo fértil. B, vista frontal da bráctea. C, flor. D, brácteas da base da inflorescência. E, estame. F, gineceu. G, fruto (Santos \& Coimbra 281, UPCB). [Ilustração realizada por Dalton T. Renault].

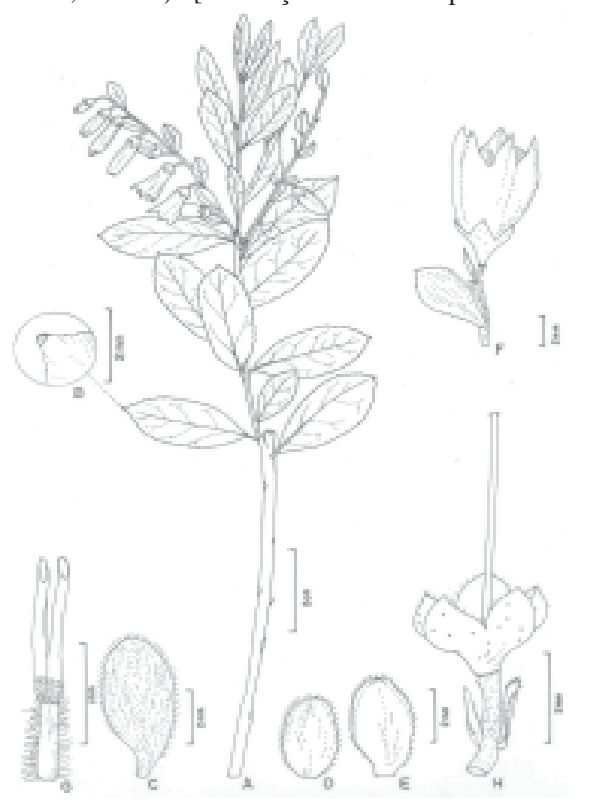

Fig. 4. Gaylussacia brasiliensis (Spreng.) Meisn. var. brasiliensis. A, ramo fértil. B, detalhe da glândula. C, vista frontal da bráctea. D, estame. E, gineceu. F, fruto. G, flor (Silva et al. 57, UPCB). Ilustração realizada por Dalton T. Renault. 


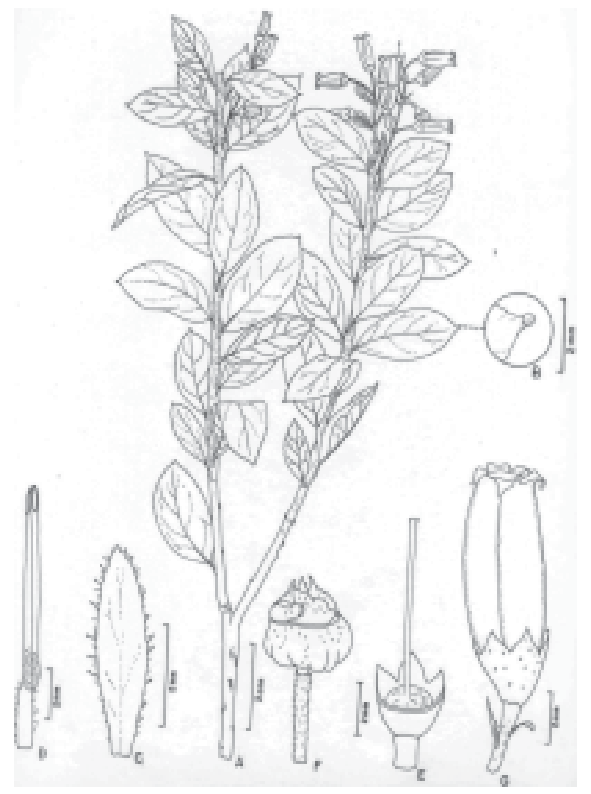

Fig. 5. Gaylussacia arassatubensis R.R. Silva \& Cervi. A, ramo fértil. B, detalhe da glândula. C, bráctea. D-E, brácteas da base da inflorescência. F, flor. G, estame. H, flor sem corola (Santos, Fernandes \& Coimbra 278, UPCB). Ilustração realizada por Dalton T. Renault.

Recebido: 20 fevereiro 2009. 